\title{
O cenário da Educação Profissional Continuada em Contabilidade na cidade de Vitória da Conquista
}

\author{
Alef Silva Almeida ${ }^{2}$
}

Márcia Mineiro²

Resumo: Impulsionada por forte influência da globalização e do surgimento constante de conhecimentos, a Educação Profissional Continuada (EPC) tem deixado de ser um desejo voluntário e individual e se tornado uma necessidade. O objetivo desta pesquisa é verificar o cenário da EPC em Contabilidade no município de Vitória da Conquista, Bahia, comparando-o com as preferências de estudantes concluintes na área. Para isso, neste trabalho, utilizou-se a abordagem predominantemente qualitativa, com forma de construção de pensamento indutiva. Trata-se de um survey, apoiado por pesquisas bibliográficas e eletrônicas, com coleta de dados por meio de Questionário, Grupo Focal e Observação Sistemática. Este estudo contribui para o campo acadêmico-científico por trazer um novo material sobre a Educação Profissional Continuada, e ainda para os campos profissional e social, por proporcionar informações de subsídio para a criação de cursos de formação continuada que possam atender às demandas de recémformados. Os resultados apontaram que as opções de Educação Profissional Continuada em Contabilidade em Vitória da Conquista não suprem as demandas dos estudantes, sobretudo porque a maior parte dos cursos é na modalidade a distância, oferecidos por instituições privadas e com poucas opções de áreas.

Palavras-chave: Contabilidade. Educação Profissional Continuada. Perspectivas profissionais. Vitória da Conquista.

\begin{abstract}
Boosted by the strong influence of Globalization and the constant emergence of new knowledge, Continuing Professional Education has been ceasing of being a voluntary and individual desire and has become a necessity. The objective of this research is to verify Accouting Continuing Professional Education options in Vitoria da Conquista's city, comparing it with the preferences of the students in the area. For this, the research opted for a predominantly qualitative approach, with a inductive form of thinking. It is a survey, supported by bibliographical and electronic researches, with data collection made through a questionnaire, focus group and systematic observation. The result of this study is relevant in the academic-scientific field for bringing a new material on Continuing Professional Education, and also in the professional and social fields, for providing subsidiary information for the creation of continuing education courses that can attend the demands of the newly graduated students. The results showed that Continuing Professional Education in Vitória da Conquista options do not meet the demands of the studentes, mainly because most of the courses are by E-Learning, offered by private institutions and with few options of areas.
\end{abstract}

Keywords: Accounting. Continuing Professional Education. Professional perspectives. Vitória da Conquista.

1 Bacharel em Contabilidade pela Universidade Estadual do Sudoeste da Bahia (UESB). Pós-Graduando (Especialização) em Finanças e Controladoria pela Faculdade de Guanambi. Pesquisador do Grupo de Pesquisa em Educação Contábil (GPEC) da UESB. E-mail: alefsilvaalmeida@hotmail.com.

2 Bacharela em Contabilidade e licenciada em Pedagogia pela Universidade Estadual do Sudoeste da Bahia (UESB). Mestre em Contabilidade pela Fundação Visconde de Cairu (FVC). Doutoranda em Educação pela Universidade Federal da Bahia (UFBA). Professora assistente na UESB, pesquisadora do Grupo de Pesquisa em Educação Contábil (GPEC) e Grupo de Pesquisa de Educação, Didática e Ludicidade (GEPEL). E-mail: periciacontroladoria@yahoo.com.br. 


\section{Introdução}

As mudanças socioeconômicas que vêm ocorrendo no mundo com o passar dos anos, aliadas à globalização, têm criado um novo cenário para os profissionais de Contabilidade. Se no passado apenas o nível técnico era suficiente para o desempenho das atividades contábeis, nos dias atuais, a necessidade de conhecimento é cada vez maior. Assim, percebe-se a importância da Educação Profissional Continuada (EPC), uma vez que, como afirma o Conselho Federal de Contabilidade (CFC), a EPC pode ser conceituada como a atividade de atualização dos conhecimentos e competências técnicas e profissionais, das habilidades multidisciplinares e da elevação do comportamento social, moral e ético dos profissionais da Contabilidade (BRASIL, 2017).

A Educação Profissional Continuada já é uma realidade para os profissionais de Contabilidade. Segundo a Pesquisa Perfil do Profissional Contábil (CFC, 2013), somente no período de 2009 a 2013, houve uma diminuição de 25,4\% no número de técnicos contábeis. Em contrapartida, observou-se um aumento significativo no número do profissionais com ensino superior, pós-graduação, mestrado e doutorado (26,6\%), o que deixa nítido que a qualificação tem-se tornado um fator essencial na área.

Todavia, as investigações teórico-empíricas sobre a temática ainda são incipientes, sendo a maior parte dos trabalhos direcionada para a área de Auditoria, uma vez que, até pouco tempo, a EPC era obrigatória somente para esse segmento da profissão contábil. Corroborando essa informação, Miranda et al. (2013, p. 86) cita a escassez de estudos sobre a Educação Contábil em seu artigo sobre a produção científica entre doutores nos anos de 2005 a 2009, ao constatar que a linha de pesquisa Educação e Pesquisa Contábil “tem o menor percentual de trabalhos defendidos, sendo que, ao se analisar especificamente os trabalhos em Educação Contábil, esse percentual cai para 4\%, revelando o interesse ainda embrionário [...] pela área."

Alguns dos poucos trabalhos encontrados na temática foram "O uso da educação profissional continuada como instrumento de manutenção do conhecimento da profissão contábil: um estudo de campo nos escritórios de contabilidade em Caicó-RN” (2015), de Pablo Reife Brito; “Atitudes e opiniões dos Alunos do Curso de graduação em Ciências Contábeis quanto a cursar Pós-Graduação: Um estudo de caso em uma Universidade Pública" (2006), de Geraldo Alemandro Leite Filho" e Franco Coelho Rodriguez e "Um estudo sobre a Educação Continuada dos profissionais da área contábil de Criciúma/SC” (2012), de Taíse Fernandes Cantelli.

Diante desse cenário, desencadeou-se a seguinte problemática: As opções de Educação Profissional Continuada em Vitória da Conquista são capazes de atender as demandas dos estudantes prestes a se formar em Contabilidade? Buscando responder a essa questão, o objetivo geral deste trabalho é verificar o cenário da EPC em Contabilidade nesse município, comparando-o com as preferências de estudantes concluintes na área. Este artigo trata a EPC sob o olhar dos estudantes concluintes do curso de Ciências Contábeis na Universidade Estadual do Sudoeste da Bahia (UESB), no ano de 2017. Como hipótese, conjectura-se, a priori, que as opções em EPC na cidade de Vitória da Conquista não são capazes de suprir a demanda dos estudantes concluintes, em virtude da quantidade limitada de cursos. 
O resultado deste estudo é relevante no campo acadêmico e científico porque traz um material contemporâneo sobre a Educação Profissional Continuada, uma área em que os estudos ainda são incipientes e voltados para a EPC, principalmente quando realizada de forma obrigatória. É relevante também para os campos profissional e social, porque apresenta informações que subsidiarão as Instituições Superiores (IES) na criação de cursos que possam atender às perspectivas dos profissionais da Contabilidade. Ademais, contadores que atuam no mercado podem obter proveito deste estudo, uma vez que terão um panorama sobre a profissão contábil sob a ótica da Educação Profissional Continuada. O trabalho justifica-se ainda porque discute um assunto em voga, já que recentemente a norma que trata da EPC para profissionais de Contabilidade passou por alterações e teve uma abrangência maior.

Ademais, como as investigações científicas que versam sobre o ensino na Contabilidade são escassas (PASSOS, MARTINS, 2006), este estudo pode potencializar um debate importante, contribuindo com os programas de Contabilidade para a redefinição de suas estratégias, público-alvo e temáticas.

$\mathrm{O}$ artigo divide-se em cinco seções: Na primeira, apresentam-se o tema e os objetivos do estudo; na segunda, o propósito é conceituar a temática e embasar a pesquisa; na terceira seção, apresentam-se os procedimentos metodológicos adotados e, por fim, a análise dos dados e as considerações finais.

\section{Revisão de literatura}

Neste tópico, contempla-se a evolução da Ciência Contábil e, consequentemente, da Educação Profissional Continuada, bem como apresenta-se uma visão geral sobre perspectivas profissionais.

\section{A Ciência Contábil}

Para exercer a profissão de Contador, um dos requisitos é ser graduado em Ciências Contábeis, ou seja, é indispensável a Educação Contábil formal. Para Vianna (2006, p. 130), o processo educacional representa "tudo aquilo que pode ser feito para desenvolver o ser humano e, no sentido estrito, que pode proporcionar a instrução e o desenvolvimento de competências e habilidades". A Educação Contábil consiste, portanto, em um processo de construção do conhecimento voltado para a Ciência Contábil.

A emergência de um mercado consumidor em expansão, em conjunto com a evolução do Ensino Superior, tem provocado um aumento crescente da demanda por cursos de graduação (VERHINE e FREITAS, 2012). Essa necessidade de aperfeiçoamento profissional é inerente à globalização, um processo de abertura de fronteiras e geração de um espaço mundial comum pelo qual o mundo vem passando nas últimas décadas (DOWBOR, IANNI e RESENDE, 1997). Nessa nova perspectiva, o capital intelectual torna-se um elemento-chave no contexto organizacional, e o contador está no centro dessa lógica. Novos modelos de negócios globais significam a mudança no papel do Contador tradicional, que passa de uma posição de registro de contas para alguém com senso de liderança e capaz de gerenciar equipes, exercendo, portanto, um julgamento rigoroso e transparente das diversas situações nos negócios (KLIBI e OUSSII, 2012, traduzido pelos autores).

\begin{tabular}{|l|c|c|c|c|c|c|c|c|} 
Cadernos de Ciências Sociais Aplicadas & ano XVI & vol. 16 & $n^{\circ} 28$ & págs. 8 -24 & jul./dez: 2019 & UESB & Vitória da Conquista/BA & pág. 10 \\
\hline
\end{tabular}


No Brasil, a Resolução número 10 de 2004, do Conselho Nacional de Educação e do Conselho de Ensino Superior (CNE/CES), que institui as diretrizes curriculares nacionais para o curso de graduação em Ciências Contábeis - bacharelado, lista as competências e habilidades previstas para a graduação em Contabilidade: utilização, demonstração, elaboração, aplicação, desenvolvimento e execução de todo o conhecimento contábil em forma interdisciplinar, dinâmica e holística. Assim, traça-se o perfil desejado do profissional de Contabilidade, uma figura proativa, multifacetada e capaz de propor soluções para os mais diferentes problemas.

\section{Educação Profissional Continuada}

Para executar o que lhe é cabível com precisão e rigor, o Contador deve buscar um aperfeiçoamento constante, por meio da Educação Profissional Continuada (EPC), conceituada pelo Conselho Federal de Contabilidade (CFC), na Norma Brasileira de Contabilidade (NBC) $n^{\circ} 12$ da seguinte forma:

A atividade que visa manter, atualizar e expandir os conhecimentos e competências técnicas e profissionais, as habilidades multidisciplinares e a elevação do comportamento social, moral e ético dos profissionais da contabilidade, como características indispensáveis à qualidade dos serviços prestados e ao pleno atendimento das normas que regem o exercício da profissão contábil. (BRASIL, 2017, p.1).

O objetivo principal da NBC é fomentar a Educação Profissional Continuada dos profissionais de Contabilidade no Brasil, obrigatória para profissionais que estejam inscritos no Cadastro Nacional de Auditores Independentes (CNAI), que exerçam ou não a atividade de auditoria independente, ou que estejam inscritos no Cadastro Nacional de Peritos Contábeis (CNPC). Essa exigência se estende aos profissionais registrados em determinadas agências reguladoras ou que exerçam funções específicas em instituições financeiras.

Dentro da Contabilidade existe, portanto, um grupo de profissionais sujeito a um programa de Educação Profissional Continuada obrigatório e outro grupo que realiza a EPC por conta própria. Conforme Souza e Diejl (2008, p. 57), “enquanto na obrigatória a certificação é uma exigência legal para o exercício da profissão, na voluntária é uma iniciativa pessoal do interessado visando obter melhores condições para uma contínua, segura e competitiva carreira profissional". Nessa mesma perspectiva, Oliveira e Nascimento (2018, p. 89) afirmam que, para parte dos profissionais que cumprem a EPC de forma não obrigatória, "as atividades [...] são adequadas para garantir o aperfeiçoamento e atualização dos profissionais, levando-se em conta a iniciativa que o profissional deve possuir de escolher as atividades que lhe agregarão mais conhecimentos". Nesse sentido, os autores defendem a premissa que o profissional deve se manter atualizado e, isso, é indispensável para todos os profissionais da área contábil.

$\mathrm{Na}$ observância da lei, somente o curso superior já seria capaz de suprir todos os conhecimentos necessários para a atuação em Contabilidade, essa ideia, entretanto, tem sido bastante contraposta (IBRACON, 2014). Nesta pesquisa, entende-se que os cursos de bacharelado, de uma forma geral, 
fornecem apenas a formação básica necessária para que o Contador atue nas diversas áreas de sua profissão.

Essa formação básica oferecida pelo curso de Ciências Contábeis é um conjunto de conhecimentos gerais e amplos sobre Contabilidade e suas áreas correlatas, que visam possibilitar a atuação do profissional, enquanto Contador. Assim, é notório que somente a graduação não é capaz de suprir à quantidade de conhecimento necessária para proporcionar ao profissional uma evolução e a melhoria de sua carreira.

\section{O nível de instrução do Contador brasileiro}

A evolução dos profissionais de Contabilidade é uma tendência que tem-se refletido em um número ascendente de profissionais com nível superior e uma constante diminuição no número de técnicos em Contabilidade, situação apurada nas pesquisas do Perfil do Profissional Contábil, realizadas pelo CFC, em 2009 e em 2013. A amostra da pesquisa foi de 3,1\% da população dos Contadores e Técnicos registrados nos CRCs.

Tabela 1 - Nível de instrução dos Contadores brasileiros

\begin{tabular}{lllllll}
\hline Ano & Técnicos & $\begin{array}{l}\text { Superior } \\
\text { Completo }\end{array}$ & $\begin{array}{l}\text { Pós- } \\
\text { Graduação }\end{array}$ & Mestrado & Doutorado & $\begin{array}{l}\text { Recusou } \\
\text { Responder }\end{array}$ \\
\hline 2013 & $13,40 \%$ & $42,70 \%$ & $38,10 \%$ & $5,10 \%$ & $0,60 \%$ & $0,00 \%$ \\
\hline 2009 & $38,80 \%$ & $40 \%$ & $18,10 \%$ & $1,60 \%$ & $0,20 \%$ & $0,30 \%$ \\
\hline
\end{tabular}

Fonte: CFC (2009, 2013) - Organizado pelos autores.

Com base na Tabela 1, nota-se o crescimento do interesse da classe Contábil pela Educação Profissional Continuada, seja em função das adaptações às normas de Contabilidade ao padrão internacional, seja em virtude das diversas alterações nas leis e regulamentos tributários do país, uma vez que a maior variação positiva, de acordo com a Tabela 1, refere-se à Pós-Graduação, com um aumento de $20 \%$ em um período de quatro anos.

Tabela 2 - Panorama da Pós-Graduação em Contabilidade no Brasil

\begin{tabular}{lc}
\hline \multicolumn{1}{c}{ Tipo } & 2017 \\
\hline $\begin{array}{l}\text { Programas de Pós-Graduação Mestrado }+ \\
\text { Doutorado }\end{array}$ & 15 \\
\hline Programas de Pós-Graduação Mestrado & 15 \\
\hline Programas de Pós-Graduação Mestrado Profissional & 5 \\
\hline Total & 35 \\
\hline
\end{tabular}

Fonte: Associação Nacional de Programas de Pós-Graduação em Ciências Contábeis (2017) - Organizado pelos autores.

Conforme pode ser verificado na Tabela 2, são disponibilizados aos profissionais de Contabilidade cursos que compreendem tanto apenas a área acadêmica (mestrados e doutorados), quanto aqueles que compreendem a área acadêmica e a prática profissional (mestrados profissionais). Partindo da 
premissa de que a formação continuada acadêmica é um importante requisito para um aperfeiçoamento cada vez maior do profissional da Contabilidade (CFC, 2017), foi instituído pelo órgão, em 1994, o Programa Excelência na Contabilidade, cuja proposta é intensificar a realização de cursos de pósgraduação lato sensu e stricto sensu em Contabilidade, por meio da participação financeira de projetos específicos direcionados a essa finalidade. Todavia, desde 2007, o CFC vem adotando a política de concessão de apoio financeiro somente para a realização de cursos na modalidade stricto sensu em Contabilidade.

Logo, as informações, dados e conceitos apresentados ao longo deste tópico de Revisão de Literatura serão fundamentais para sustentar o entendimento e amparo das análises vindouras.

\section{Metodologia}

O capítulo de procedimentos metodológicos descreve os métodos que foram seguidos na realização do trabalho (GIL, 2010). Assim, neste capítulo serão expostas informações concernentes ao tipo da pesquisa, população, amostra, coleta e análise de dados.

\section{Estratégia e método da pesquisa}

Neste trabalho, utilizou-se uma abordagem de pesquisa predominantemente qualitativa, escolha que se deu devido à natureza subjetiva do tema a ser pesquisado. A forma de construção do pensamento da pesquisa foi indutiva, pois, segundo Lakatos e Marconi (2003, p. 86), pela indução parte-se de "dados particulares, suficientemente constatados e, portanto, [...] o objetivo dos argumentos indutivos é levar a conclusões cujo conteúdo é muito mais amplo do que o das premissas nas quais se basearam". Essa escolha se justifica, uma vez que o problema da pesquisa parte de um contexto real e particular para tentar realizar uma generalização da relação, relacionando o fenômeno aos fatos.

Tem-se aqui, portanto, um estudo descritivo proveniente da técnica de survey. Essa modalidade permite encontrar determinadas características em um grupo específico, Babbie (2003, p. 95) afirma que “surveys são frequentemente utilizados por permitir enunciados descritivos sobre uma população" e ainda que "survey é um veículo [...] para descobrir a distribuição de traços numa amostra". Assim, essa técnica de levantamento de dados permitiu a interação com os sujeitos pesquisados para corroborar ou refutar a hipótese da pesquisa.

\section{Amostra}

Vitória da Conquista é a terceira maior cidade do estado da Bahia, contando com aproximadamente 350 mil habitantes (IBGE, 2016). Dados da Secretaria da Indústria, Comércio e Mineração do Estado da Bahia (2014) mostram que, em dez anos, o Produto Interno Bruto (PIB) de Vitória da Conquista cresceu mais de 340\%. Em 2013, o PIB foi de mais de R 4 bilhões, conferindo à cidade o título de sexta maior economia do Estado. 
Vitória da Conquista é um munícipio polarizador, tanto em oferta de serviços ou trabalho quanto em educação. A cidade conta com três IES públicas, sendo elas a Universidade Estadual do Sudoeste da Bahia (UESB), a Universidade Federal da Bahia (UFBA), e o Instituto Federal de Ciência, Educação e Tecnologia da Bahia (IFBA).

Existem, ainda, diversas instituições particulares (presenciais e a distância), entre elas destacam-se a Faculdade Independente do Nordeste (FAINOR), a Faculdade de Tecnologia e Ciências (FTC), a Faculdade Santo Agostinho (FASA), a Universidade do Norte do Paraná (UNOPAR), a Universidade Paulista (UNIP) e a Universidade Tiradentes (UNIT).

Diante desse cenário, o universo amostral desta pesquisa foi composto pelos 12 estudantes do décimo semestre do curso de Ciências Contábeis da UESB, no ano de 2017, em Vitória da Conquista, Bahia. A escolha da Instituição de Ensino se justifica pela relevância da Universidade Estadual do Sudoeste da Bahia em Vitória da Conquista, a maior IE pública da região, bem como a proximidade do pesquisador com os sujeitos da pesquisa, o que facilitou a coleta e tratamento de dados. O índice médio de participação foi de $83,3 \%$. Os respondentes foram denominados "Aluno 1", "Aluno 2" e assim por diante, visando preservar o sigilo e a confidencialidade.

O pesquisador originalmente faria parte do universo desta pesquisa, entretanto, optou-se por não participar, com o intuito de prezar pela independência do trabalho e evitar possíveis respostas tendenciadas. Dessa forma, para Lakatos e Marconi (2003, p. 193), "o pesquisador toma contato com a comunidade, grupo ou realidade estudada, mas sem integrar-se a ela". Assim, trata-se de uma pesquisa não participante.

\section{Coleta e análise de dados}

Foram utilizados três instrumentos de coleta de dados, sendo o primeiro deles o Questionário Semiaberto, cujo objetivo foi coletar informações no universo amostral sobre o nível de conhecimento sobre a Educação Profissional Continuada em Contabilidade e identificar quais as perspectivas profissionais após o fim da graduação.

Outro instrumento de coleta de dados utilizado foi Grupo Focal ou Entrevista de Grupo. Para Barbour (2009, p. 20), a Entrevista de Grupo "se baseia em gerar e analisar a interação entre participantes", essa ideia corrobora o pensamento de Morgan (1997), que afirma "o grupo focal é uma técnica de pesquisa que possibilita a obtenção de dados com base em interações grupais ao se debater um tópico específico proposto pela pesquisa." A escolha deste instrumento se deu devido à possibilidade de obtenção de novas e mais consistentes informações e a própria promoção de interação entre os entrevistados, o que coaduna com a abordagem qualitativa que valoriza a subjetividade e interação.

O grupo focal foi realizado em uma sala da UESB, e de um total de 12 presenças possíveis, 9 compareceram, o que caracteriza uma participação de 75\%. Na Entrevista de Grupo foram levantadas algumas questões similares ao que já havia sido verificado por meio do questionário, artifício utilizado com

\begin{tabular}{|l|c|c|c|c|c|c|c|c|} 
Cadernos de Cièncias Sociais Aplicadas & ano XVI & vol. 16 & $n^{\circ} 28$ & págs. 8 -24 & jul./dez: 2019 & UESB & Vitória da Conquista/BA & pág. 14 \\
\hline
\end{tabular}


a intenção de realizar uma triangulação de informações. A triangulação busca analisar um mesmo fenômeno ou objeto de pesquisa sob a ótica de uma ou mais fontes de dados (DECROP, 2004).

As informações obtidas por meio da coleta de dados foram analisadas sob a ótica da análise de conteúdo, de forma interpretativa. Com base em conceitos trazidos por Bardin (2006), inicialmente foi realizada uma pré-análise do material visando torná-lo organizado e passível de análise, partindo então a exploração do conteúdo com a decodificação das respostas mediante categorias, constatadas nas "Incidências" apresentadas nos quadros. Por fim, com base nas informações obtidas, os dados foram analisados e interpretados na tentativa de dar um significado mais amplo às respostas, vinculando-as a outros conhecimentos e comparando-as com conceitos presentes na lei e na teoria, para assim verificar a frequência ou ausência de determinados conhecimentos. Holsti, 1968 apud Chizzoti (2006, p. 115), afirma que a análise de conteúdo é uma "técnica de fazer inferências sistemáticas e objetivas, identificando as características especiais da mensagem". Nesse sentido, os autores constatam que o texto vai além daquilo que se lê, ou seja, é preciso identificar constatações implícitas para se chegar a uma conclusão.

O último instrumento de coleta de dados utilizado foi uma Observação Sistemática por meio de idas a campo em instituições de ensino que oferecem cursos e pós-graduação na área de Contabilidade na cidade de Vitória da Conquista. Essas idas a campo foram necessárias para a coleta de panfletos e a complementação de informações não obtidas por intermédio das outras fontes da pesquisa, ao todo, foram visitadas nove instituições de ensino. Foi elaborado um check-list para coletar as informações almejadas. Os nomes de instituições, valores e cursos apresentados neste artigo foram obtidos em panfletos de circulação livre. Uma vez explanados os aspectos concernentes à metodologia, apresenta-se, a seguir, a análise dos dados coletados.

\section{Apresentação e análise dos resultados}

A análise de dados é, para Lakatos e Marconi (2003, p. 167), a "tentativa de evidenciar as relações existentes entre o fenômeno estudado e outros fatores". Aqui, serão apresentados os resultados obtidos na coleta de dados, analisando-os e comparando-os com a teoria.

\section{Discentes versus Educação Profissional Continuada}

Com o intuito de compreender os sujeitos analisados e as condições em que estão inseridos, traçou-se um breve perfil socioeconômico dos participantes. Das 11 respostas obtidas sobre gênero, 8 revelam ser do gênero masculino e 3 do feminino; no que tange à idade, 8 deles tinham entre 20 e 25 anos, 2 entre 26 e 30 anos e somente 1 de 31 a 35 anos. Todos afirmaram residir em Vitória da Conquista Bahia. Sobre a renda, 6 deles disseram receber entre um e dois salários mínimos, ao passo que 4 recebiam de dois até cinco salários mínimos e 2 até um salário mínimo. Todos dispõem de ocupação profissional, 8 deles no setor privado, enquanto somente 4 trabalhavam no setor público.

Percebe-se um perfil jovem e já inserido no mercado de trabalho, predomina, no entanto, a remuneração mais baixa, uma vez que esses sujeitos ainda estão dando os primeiros passos na carreira 
profissional. Nota-se, além disso, a alta taxa de empregabilidade da profissão, principalmente nas empresas privadas. A pesquisa desenvolvida por Martins (2017) “As Perspectivas Profissionais dos Estudantes de Ciências Contábeis na Universidade Federal de Goiás" aponta uma taxa de empregabilidade de seus participantes - também graduandos - de $74 \%$, o que mostra que essa não é uma situação isolada deste estudo.

A predominância do setor privado é comum entre profissionais mais jovens, principalmente em virtude da falta de experiência no currículo, o que acarreta em um trabalho simples, ocupando muito tempo e com uma remuneração abaixo do que se deseja (CERQUEIRA, 2017). Essa situação é contornada conforme o profissional adquire experiências profissionais e se qualifica. Nessa perspectiva, está a figura da Educação Profissional Continuada. Assim, é imprescindível verificar o nível de conhecimento e as perspectivas dos sujeitos sobre esse tema.

Quadro 1 - O que você entende por Educação Profissional Continuada?

\begin{tabular}{|c|c|c|c|}
\hline Sujeito & $\begin{array}{c}\text { O que você acredita que seja "Educação } \\
\text { Profissional Continuada em Contabilidade"? }\end{array}$ & Incidências & Parágrafo Síntese \\
\hline 1 & $\begin{array}{l}\text { Continuar se especializando na área, e atento às } \\
\text { atualizações que regem a profissão (sic). }\end{array}$ & \multirow{11}{*}{$\begin{array}{l}\text { Continuidade } \\
\text { dos estudos após } \\
\text { a graduação; } \\
\text { Segmento na } \\
\text { área docente; } \\
\text { Obrigatoriedade } \\
\text { para certas áreas; } \\
\text { Aprofundamento } \\
\text { em áreas } \\
\text { específicas. }\end{array}$} & \multirow{11}{*}{$\begin{array}{c}\text { A maior parcela dos } \\
\text { discentes considera } \\
\text { a Educação } \\
\text { Profissional } \\
\text { Continuada o } \\
\text { prosseguimento dos } \\
\text { estudos após a } \\
\text { graduação, com o } \\
\text { objetivo de } \\
\text { especializar-se em } \\
\text { uma área e obter } \\
\text { mais } \\
\text { conhecimentos. } \\
\text { Apenas um dos } \\
\text { respondentes citou } \\
\text { que a Educação } \\
\text { Profissional } \\
\text { Continuada é } \\
\text { obrigatória para } \\
\text { uma parte da classe } \\
\text { Contábil. }\end{array}$} \\
\hline 2 & Continuar os estudos após a graduação (sic). & & \\
\hline 3 & $\begin{array}{l}\text { Que o profissional contábil continue se atualizando e } \\
\text { aprimorando os seus conhecimentos (sic). }\end{array}$ & & \\
\hline 4 & Possivelmente um segmento na área docente (sic). & & \\
\hline 5 & $\begin{array}{l}\text { Seria a maneira de continuar adquirindo } \\
\text { conhecimentos que agregue algo novo a profissão. Ou } \\
\text { seja, continuar estudando (sic). }\end{array}$ & & \\
\hline 6 & Pós-graduação na área contábil (sic). & & \\
\hline 7 & $\begin{array}{l}\text { Como o nome já diz, uma continuação da } \\
\text { Contabilidade, ou seja, um acompanhamento depois } \\
\text { da graduação (sic). }\end{array}$ & & \\
\hline 8 & $\begin{array}{l}\text { É o estudo continuo que o profissional de } \\
\text { contabilidade necessita ter, após a sua graduação para } \\
\text { que possa tanto aprimorar aquilo que a faculdade } \\
\text { apenas introduziu como obter novos conhecimentos a } \\
\text { respeito do mundo contábil afim de possibilitar um } \\
\text { melhor desempenho perante o seu cliente (sic). }\end{array}$ & & \\
\hline 9 & $\begin{array}{l}\text { Busca de novos conhecimentos através de um } \\
\text { aprofundamento em determinada área. }\end{array}$ & & \\
\hline 10 & $\begin{array}{l}\text { Acredito que seja o ato de dar prosseguimento aos } \\
\text { estudos em contabilidade, como fazer uma } \\
\text { especialização, um mestrado, enfim...creio também, } \\
\text { que implique naquela premissa de que nunca é tarde } \\
\text { para dar um passo adiante, sendo assim, vê-se a } \\
\text { necessidade de se permanecer atualizado e estar } \\
\text { sempre na trilha pela busca de uma possível ascensão } \\
\text { do conhecimento contábil (sic). }\end{array}$ & & \\
\hline 11 & $\begin{array}{l}\text { Forma de atualização e aprimoramento dos } \\
\text { conhecimentos através de cursos, etc. Em alguns } \\
\text { casos esta é obrigatória (sic). }\end{array}$ & & \\
\hline
\end{tabular}

Fonte: Dados da Pesquisa - Elaborada pelos autores. 
Todos os respondentes citaram, ainda que indiretamente, o prosseguimento dos estudos em Contabilidade como o que entendem por Educação Continuada. Essa resposta, por si só, está correta, entretanto, não abarca a grande possibilidade de atividades que podem ser desenvolvidas após a graduação, bem como as nuances específicas para a área da Contabilidade. Dessa forma, verifica-se uma limitação no conhecimento desses sujeitos. Pouquíssimos deles citaram aspectos importantes da EPC em Contabilidade trazidos pela NBC $n^{\circ} 12$, como a manutenção e a atualização de habilidades multidisciplinares, a elevação de comportamento social, moral e ético ou a obrigatoriedade da EPC em determinados segmentos da Contabilidade, como é o caso da Auditoria e Perícia (BRASIL, 2017).

Nota-se, portanto, que os respondentes somente possuem uma noção básica sobre EPC, provavelmente advinda do próprio nome (autoexplicativo). Entretanto, falta-lhes um maior aprofundamento sobre como isso se aplica e tem sido executado dentro da Contabilidade, ainda que a considerem relevante.

\section{Educação Profissional Continuada em Vitória da Conquista}

Identificou-se a existência de onze cursos superiores em Ciências Contábeis em Vitória da Conquista, um deles em universidade pública e os demais em instituições particulares; dois presenciais e oito a distância. Os valores variaram de $\mathrm{R} \$ 279,00$ a $\mathrm{R} \$ 775,00$.

Há um grande quantitativo de cursos superiores na cidade. No Brasil, o número de cursos superiores em Ciências Contábeis passou de 384 em 1996 para 1028 em 2009. Esse aumento ocorreu em razão do crescimento econômico e do desenvolvimento social (RAMIREZ, 2011). Os cursos semipresenciais oferecem aulas semanais, enquanto os da modalidade EAD possuem encontros semestrais para a realização de provas. Constatada a existência de demanda por cursos de pós-graduação em Ciências Contábeis na cidade, tanto por parte dos alunos da UESB (conforme verificado por meio do questionário e grupo-focal) quanto, provavelmente, por parte do grande número de alunos de outras instituições, buscou-se identificar as opções de continuidade dos estudos em Contabilidade.

Quadro 2 - Opções de Formação Continuada em Contabilidade em Vitória da Conquista - Janeiro/2017.

\begin{tabular}{|c|c|c|c|c|c|}
\hline Instituição & Curso & Tipo & $\begin{array}{c}\text { Modalidad } \\
\text { e }\end{array}$ & Duração & $\begin{array}{c}\text { Mensalidad } \\
\text { e }\end{array}$ \\
\hline $\begin{array}{c}\text { Faculdade Maurício de } \\
\text { Nassau } \\
\text { (UNINASSAU) }\end{array}$ & $\begin{array}{c}\text { Auditoria e } \\
\text { Controladoria }\end{array}$ & MBA & Presencial & $\begin{array}{c}18 \text { meses } \\
\text { (aula) }+3 \\
\text { meses } \\
\text { (TCC) }\end{array}$ & $\begin{array}{l}18 x \mathrm{R} \$ \\
240,00\end{array}$ \\
\hline $\begin{array}{l}\text { Centro Unigrad de } \\
\text { Pós-Graduação } \\
\text { (UNIGRAD) }\end{array}$ & $\begin{array}{l}\text { Finanças e } \\
\text { Controladoria }\end{array}$ & Especialização & Presencial & $\begin{array}{c}12 \text { meses } \\
(\text { aula })+2 \\
\text { meses } \\
\text { (TCC) }\end{array}$ & $\begin{array}{c}\text { Matrícula } \\
\mathrm{R} \$ 100,00+ \\
16 x \mathrm{R} \$ 343,44\end{array}$ \\
\hline $\begin{array}{c}\text { Faculdade de } \\
\text { Tecnologia e Ciências } \\
\text { (FTC) }\end{array}$ & $\begin{array}{l}\text { Controladoria e } \\
\text { Finanças }\end{array}$ & Especialização & Presencial & 18 meses & $\begin{array}{l}18 \times \mathrm{R} \$ \\
370,00\end{array}$ \\
\hline $\begin{array}{c}\text { Faculdade } \\
\text { Independente do }\end{array}$ & $\begin{array}{c}\text { Planejamento e } \\
\text { Gestão Tributária }\end{array}$ & Especialização & Presencial & 18 meses & $\begin{array}{c}\text { Não } \\
\text { Informado }\end{array}$ \\
\hline
\end{tabular}




\begin{tabular}{|c|c|c|c|c|c|}
\hline \multicolumn{6}{|l|}{ Nordeste (FAINOR) } \\
\hline $\begin{array}{l}\text { Fundação Getúlio } \\
\text { Vargas (FGV/IBEN) }\end{array}$ & $\begin{array}{l}\text { Gestão Financeira, } \\
\text { Controladoria e } \\
\text { Auditoria (Obs.: } \\
\text { Exige experiência } \\
\text { em Gestão e realiza } \\
\text { Análise Curricular). }\end{array}$ & $\mathrm{MBA}$ & Presencial & 18 meses & $\begin{array}{c}\text { Não } \\
\text { Informado }\end{array}$ \\
\hline \multirow{2}{*}{$\begin{array}{l}\text { Laureate International } \\
\text { Universities } \\
\text { (UNIFACS) }\end{array}$} & Controladoria & MBA & EAD & 12 meses & $\begin{array}{c}\text { A partir de } \\
\mathrm{R} \$ 149,00\end{array}$ \\
\hline & Finanças e Banking & MBA & EAD & 12 meses & $\begin{array}{l}\text { A partir de } \\
\mathrm{R} \$ 149,00\end{array}$ \\
\hline $\begin{array}{c}\text { Instituto Dorinha } \\
\text { (UNIMES) }\end{array}$ & Gestão Tributária & $\begin{array}{c}\text { Não } \\
\text { Informado }\end{array}$ & EAD & 8 meses & $\begin{array}{c}8 \mathrm{x} \mathrm{R} \$ \\
135,00\end{array}$ \\
\hline \multirow{3}{*}{$\begin{array}{c}\text { Centro Universitário } \\
\text { Internacional } \\
\text { (UNINTER) }\end{array}$} & $\begin{array}{c}\text { Administração e } \\
\text { Financas }\end{array}$ & MBA & EAD & 9 meses & $\begin{array}{r}9 \mathrm{x} \mathrm{R} \$ \\
205,00\end{array}$ \\
\hline & $\begin{array}{c}\text { Contabilidade } \\
\text { Pública e } \\
\text { Responsabilidade } \\
\text { Fiscal }\end{array}$ & $\mathrm{MBA}$ & $\mathrm{EAD}$ & 9 meses & $\begin{array}{l}9 \mathrm{x} R \$ \\
188,00\end{array}$ \\
\hline & $\begin{array}{l}\text { Controladoria e } \\
\text { Finanças }\end{array}$ & MBA & EAD & 9 meses & $\begin{array}{r}9 \times \mathrm{R} \$ \\
205,00\end{array}$ \\
\hline \multirow{2}{*}{$\begin{array}{l}\text { Faculdade de Vitória } \\
\text { da Conquista (FAEL) }\end{array}$} & $\begin{array}{c}\text { Gestão em } \\
\text { Finanças } \\
\text { Empresariais }\end{array}$ & Especialização & EAD & 12 meses & $\begin{array}{l}12 x \mathrm{R} \$ \\
191,13\end{array}$ \\
\hline & $\begin{array}{c}\text { Auditoria e Perícia } \\
\text { Contábil }\end{array}$ & Especialização & EAD & 12 meses & $\begin{array}{l}12 \times \mathrm{R} \$ \\
191,13\end{array}$ \\
\hline
\end{tabular}

Fonte: Dados da Pesquisa - Elaborada pelos autores.

Apesar da existência de treze cursos de pós-graduação na cidade, distribuídos entre nove instituições, nota-se que somente cinco são na modalidade presencial, não por coincidência, são os que possuem os valores mais elevados. Consequentemente, a falta de pós-graduação na universidade pública deixa os estudantes à mercê das instituições privadas ou obriga-os a se deslocar para outras localidades do estado ou até mesmo do país.

Também é preocupante a ausência de cursos na modalidade stricto sensu, percebe-se, portanto, que o foco nas instituições privadas tem sido somente o mercado de trabalho, deixando a docência e a pesquisa em segundo plano. A preferência pela modalidade lato sensu por parte das faculdades privadas tem uma justificativa: esses cursos são os mais procurados, pois se voltam para o mercado de trabalho (logo, sem cunho acadêmico). Vale ressaltar, também, os processos de seleção pouco rigorosos em comparação com os cursos stricto sensu. Em entrevista ao jornal O Globo, o diretor da Fundação Getúlio Vargas (FGV) - instituição particular - afirma que a pós lato sensu possui seis mil inscritos, contra somente quatrocentos e trinta da pós stricto sensu (O GLOBO, 2017).

Os estudantes também possuem suas preferências em relação aos temas estudados durante a graduação, assim, uma grande quantidade de cursos pode não necessariamente atender à demanda do 
local. Nesse sentido, buscou-se verificar quais disciplinas despertaram o maior interesse dos discentes durante o curso.

Tabela 3 - Nível de afinidade com áreas da Contabilidade.

\begin{tabular}{lc}
\hline \multicolumn{1}{c}{ Opções } & $\begin{array}{c}\text { Resultados (Em uma escala de 1 a 5, sendo 5 muito } \\
\text { afinidade e 1 pouca afinidade) }\end{array}$ \\
\hline Controladoria & 4,1 \\
\hline Perícia Contábil & 3,9 \\
\hline Auditoria & 3,4 \\
\hline Contabilidade de Custos & 3,3 \\
\hline Contabilidade Tributária & 3,2 \\
\hline Outra & 3,2 \\
\hline Contabilidade Pública & 2,8 \\
\hline Análise das Demonstrações Contábeis & 2,7 \\
\hline
\end{tabular}

Fonte: Dados da Pesquisa - Elaborada pelos autores.

Observou-se que as matérias de natureza mais gerencial obtiveram maior nota dos alunos. É o caso de Controladoria, Perícia Contábil e Auditoria. No entanto, todas as outras áreas também alcançaram uma pontuação expressiva, de modo que nenhuma delas teve percentual de afinidade abaixo de 50\%.

A síntese das opções em pós-graduação na cidade de Vitória da Conquista, por área de conhecimento, Quadro 3, mostra que 69\% dos cursos são voltados para as áreas de Controladoria e Auditoria, enquanto os outros 31\% restantes se dividem, respectivamente, em Contabilidade Tributária (15\%), Contabilidade Pública (8\%) e Perícia Contábil (8\%).

A maioria dos cursos são voltados para as áreas de Controladoria, Auditoria e Finanças. Logo, esse resultado está parcialmente em consonância com o que foi verificado anteriormente, em relação às preferências dos estudantes. Entretanto, apesar da grande oferta de cursos nessa área, nota-se a escassez em Análise de balanços, Contabilidade de Custos ou na área pública, por exemplo.

A situação apresentada torna-se ainda mais deficiente ao desconsiderar cursos da modalidade EAD, uma vez que, ao serem questionados sobre possíveis cursos nesse formato, os estudantes não manifestaram interesse, conforme verifica-se no Quadro 3.

Quadro 3 - Modalidade de Ensino

\begin{tabular}{|c|c|c|c|c|}
\hline Sujeito & $\begin{array}{l}\text { Modalidade } \\
\text { Escolhida }\end{array}$ & $\begin{array}{l}\text { Com base na resposta da } \\
\text { pergunta anterior } \\
\text { (modalidade), explique o } \\
\text { motivo de sua escolha. }\end{array}$ & Incidências & Parágrafo Síntese \\
\hline 1 & Semipresencial & $\begin{array}{l}\text { Seria mais fácil conciliar outras } \\
\text { atividades } \\
\text { semipresencial. }\end{array}$ & \multirow{5}{*}{$\begin{array}{l}\text { Conciliar } \\
\text { atividades } \\
\text { (flexibilidade); } \\
\text { Qualidade e } \\
\text { aproveitamento } \\
\text { no ensino } \\
\text { presencial. }\end{array}$} & \multirow{5}{*}{$\begin{array}{lr}\text { Percebe-se } & \text { certa } \\
\text { preferência } & \text { dos } \\
\text { estudantes } & \text { pela } \\
\text { modalidade presencial, } \\
\text { sendo a principal } \\
\text { justificativa para essa } \\
\text { preferência a melhor } \\
\text { qualidade do ensino e } \\
\text { por fornecer um } \\
\text { conhecimento mais }\end{array}$} \\
\hline 2 & Semipresencial & Economia de tempo. & & \\
\hline 3 & Presencial & $\begin{array}{l}\text { O contato real é essencial para } \\
\text { a construção do conhecimento. }\end{array}$ & & \\
\hline 4 & Presencial & Por ter uma qualidade melhor & & \\
\hline 5 & Presencial & $\begin{array}{l}\text { Acredito que o conhecimento } \\
\text { presencial é bem mais } \\
\text { proveitoso e produtivo. }\end{array}$ & & \\
\hline
\end{tabular}




\begin{tabular}{|c|c|c|c|}
\hline 6 & Semipresencial & $\begin{array}{l}\text { Minha concentração é melhor e } \\
\text { tenho a possibilidade de tirar } \\
\text { dúvidas. }\end{array}$ & \multirow{5}{*}{ 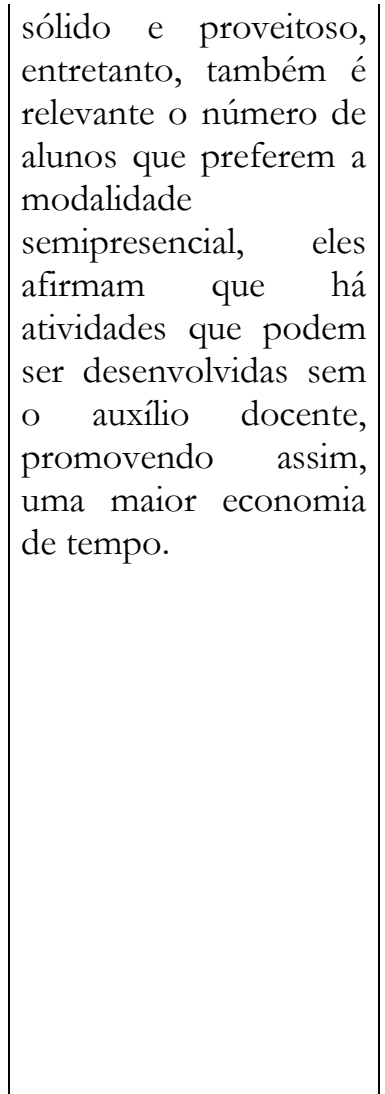 } \\
\hline 7 & Semipresencial & $\begin{array}{l}\text { Acredito que o aprendizado se } \\
\text { dá com o acompanhamento de } \\
\text { perto pelo professor mas que } \\
\text { algumas atividades poderiam } \\
\text { tranquilamente ser realizadas } \\
\text { extraclasse (sic). }\end{array}$ & \\
\hline 8 & Presencial & $\begin{array}{l}\text { Acredito que as aulas } \\
\text { presenciais possibilitam ao } \\
\text { aluno um melhor aprendizado } \\
\text { já que este conta com o } \\
\text { professor a todo o momento } \\
\text { para sanar as dúvidas. }\end{array}$ & \\
\hline 9 & Presencial & $\begin{array}{l}\text { Aulas presenciais permitem } \\
\text { uma troca de conhecimentos } \\
\text { mais aprofundados. }\end{array}$ & \\
\hline 10 & Semipresencial & $\begin{array}{l}\text { Permite o contato com o } \\
\text { docente para explanações e } \\
\text { esclarecimentos, bem como, } \\
\text { existe a flexibilidade de tempo } \\
\text { para se dedicar um pouco mais } \\
\text { aos estudos e deveres do curso. }\end{array}$ & \\
\hline 11 & Presencial & Melhor qualidade do ensino. & \\
\hline
\end{tabular}

Fonte: Dados da Pesquisa - Elaborada pelos autores.

No Quadro 3, é possível perceber que há uma divisão equilibrada entre as opções presencial (54\%) e semipresencial (46\%) Entre aqueles que preferem a primeira modalidade, o principal motivo citado é a melhor qualidade no ensino, afinal, esta é uma das maiores dificuldades do ensino a distância. (NETTTO, GIRAFFA e FARIA, 2010) Isso também explica a ausência dos cursos totalmente a distância.

Outro aspecto decisivo para aqueles que têm como preferência a modalidade presencial é a troca de conhecimentos entre os discentes. Esse aspecto possui seu embasamento na teoria sociointeracionista de Lev Vygotsky. Na chamada perspectiva sociointeracionista, sociocultural ou sócio-histórica, abordada por Vygotsky, a relação entre o desenvolvimento e a aprendizagem está atrelada ao fato de o humano viver em meio social, sendo as relações a alavanca para o aprendizado e o desenvolvimento. Isso quer dizer que os processos caminham juntos, ainda que não em paralelo (RABELLO; PASSOS, 2010). Entende-se, portanto, o processo de Educação e aprendizado não como algo individual, mas sim como um caminho que também sofre influências de fatores e aspectos externos.

Se consideramos somente os cursos na modalidade presencial e semipresencial, só figuram duas áreas do conhecimento: Controladoria, Finanças e Auditoria (80\%) e Contabilidade Tributária (20\%), isso caracteriza a escassez para várias outras áreas da Contabilidade que também despertam o interesse dos discentes em Ciências Contábeis da UESB. 
Apesar disso, sabe-se que a EPC não se limita a cursos de pós-graduação, mas também abrange cursos de extensão, seminários, congressos etc. Esses eventos são constantemente ofertados na cidade por intermédio do Conselho Regional de Contabilidade (CRC-BA), da Faculdade Independente do Nordeste (FAINOR), da Universidade Estadual do Sudoeste da Bahia (UESB) e de outras instituições.

Dessa forma, ainda que não ingresse em uma pós-graduação após a conclusão do curso superior, o profissional tem uma série de atualizações e aprimoramentos que podem ser realizados em curto período de tempo. Todavia, ainda assim, pode-se caracterizar uma situação de demanda reprimida, uma vez que, apesar do expressivo número de opções para a formação continuada dos discentes de Ciências Contábeis em Vitória da Conquista, elas não atendem completamente às perspectivas dos estudantes por diversos motivos, em síntese:

(I) Os cursos são em sua maioria EAD (os estudantes preferem modalidades com contato presencial);

(II) Todas as opções são oferecidas por instituições particulares;

(III) Há pouca diversidade de áreas, sendo a maior parte voltada apenas para Controladoria e Auditoria em sentido amplo;

(IV) Não há cursos na modalidade stricto sensu.

Assim, de posse da análise de dados, tanto as hipóteses puderam ser ratificadas, quanto os objetivos atingidos. Conforme é possível verificar no capítulo das considerações finais, apresentado a seguir.

\section{Considerações finais}

Este trabalho baseou-se na metodologia da pesquisa científica para alcançar os resultados propostos. Em virtude da subjetividade do tema, optou-se por uma abordagem predominantemente qualitativa, por meio de um levantamento (survey), apoiado em pesquisas documentais e bibliográficas. Foram realizadas consultas na literatura objetivando uma melhor compreensão do tema, seguida da aplicação de instrumentos de coleta de dados (questionário semiaberto, grupo focal e observação sistemática) para responder à problemática, o universo amostral dessa pesquisa foi composto pelos doze estudantes do décimo semestre do curso de Ciências Contábeis da UESB, no ano de 2017, em Vitória da Conquista, Bahia.

A seguinte questão foi levantada: as opções de Educação Profissional Continuada em Vitória da Conquista são capazes de atender as demandas dos estudantes prestes a se formar em Contabilidade? Como hipótese, acreditava-se que as alternativas em EPC na cidade de Vitória da Conquista não eram capazes de suprir a demanda dos estudantes concluintes em virtude da quantidade limitada de cursos. Essa hipótese foi testada e parcialmente ratificada. Chegou-se à seguinte resposta para o problema: as opções em EPC em Contabilidade na cidade de Vitória da Conquista não são capazes de suprir a demanda dos estudantes concluintes em Ciências Contábeis, especialmente em virtude da grande maioria dos cursos 
serem na modalidade a distância e, além disso, oferecidos por instituições privadas, além da pouca variedade de áreas e ausência de cursos na modalidade stricto sensu.

O objetivo geral da pesquisa foi verificar o cenário da EPC em Contabilidade no município de Vitória da Conquista, comparando-o com as perspectivas de estudantes concluintes na área. Foram identificados treze cursos que podem ser caracterizados como EPC. Entretanto, a maior parte deles é EAD, uma modalidade de ensino que não desperta o interesse dos discentes por conta de uma possível qualidade inferior do ensino e da falta de interação com os sujeitos no processo ensino-aprendizagem. Quanto às suas perspectivas, percebeu-se que a maior parte dos concluintes possuem o desejo de investir nos estudos após a conclusão da graduação, com um olhar direcionado para o mercado de trabalho, sendo assim, optam principalmente por cursos lato sensu, as chamadas especializações. Eles entendem que essa Educação Continuada é capaz de proporcionar maior reconhecimento na carreira e ascensão profissional, as áreas que lhes despertam maior interesse são aquelas com cunho gerencial, como é o caso da Auditoria e da Controladoria.

Com base nos resultados obtidos, nota-se que a Educação Profissional Continuada em Contabilidade é uma realidade não só para os discentes que ainda estão na graduação, mas também para os profissionais já atuantes no mercado. Assim, é preciso que as instituições de ensino públicas e privadas forneçam opções nessa área para suprir a demanda. Ao concluir a graduação, os estudantes das IES públicas ficam à mercê de instituições privadas que, muitas vezes, cobram custos altos para os cursos na modalidade presencial, o que pode inviabilizar uma possível formação continuada.

Como uma das sugestões de pesquisas futuras, propõe-se um levantamento com profissionais atuantes no mercado para identificar se estes possuem conhecimento acerca do tema e se têm praticado a Educação Profissional Continuada (nas opções oferecidas na cidade).

Entende-se, portanto, que este estudo traz uma clara contribuição tanto para o pesquisador quanto para a Ciência Contábil, mediante a criação de um material literário em uma área cuja pesquisa ainda é incipiente. Sua relevância se estende também para toda a classe contábil, uma vez que pode servir como fonte de consulta para Instituições de Ensino Superior que visem instituir cursos de formação continuada, para estudantes concluintes em Ciências Contábeis, ainda inseguros sobre as suas perspectivas educacionais, bem como, para profissionais graduados que desejam adquirir conhecimentos.

\section{Referências}

BABBIE, Earl. Métodos de Pesquisa Survey. 2. ed. Belo Horizonte: UFMG, 2003.

BARBOUR, Rosalina. Grupos Focais. 1 ed. Porto Alegre: Artmed, 2009.

BARDIN, L.. Análise de conteúdo (L. de A. Rego \& A. Pinheiro, Trads.). Lisboa: Edições 70. (Obra original publicada em 1977), 2006.

BRASIL. CONSELHO FEDERAL DE CONTABILIDADE. Norma Brasileira de Contabilidade NBC PG 12. 2017. Disponível em: < http://www1.cfc.org.br/sisweb/SRE/docs/NBCPG12(R2).pdf>. Acesso em: 20 jan. 2018.

\begin{tabular}{l|c|c|c|c|c|c|c|c|} 
Cadernos de Ciências Sociais Aplicadas & ano XVI & vol. 16 & $n^{\circ} 28$ & págs. 8 -24 & jul./dez: 2019 & UESB & Vitória da Conquista/BA & pág. 22 \\
\hline
\end{tabular}


CONSELHO NACIONAL DE EDUCAÇÃO. Resolução CNE/CES n n 10. 2004. Disponível em: <http://portal.mec.gov.br/cne/arquivos/pdf/rces10_04.pdf>. Acesso em: 19 mar. 2016.

2016. Disponível

INSTITUTO BRASILEIRO DE GEOGRAFIA E ESTATÍSTICA. Vitória da Conquista. em: <http://cidades.ibge.gov.br/xtras/perfil.php?codmun=293330> Acesso em 02 fev. 2017.

CERQUEIRA, Cezar Marães. Mercado de Trabalho para o jovem: Setor Público ou Privado?. 2017. Disponível em: <https://www.portaleducacao.com.br/conteudo/artigos/iniciacaoprofissional/mercado-de-trabalho-para-o-jovem-setor-publico-ou-privado/52976>. Acesso em: 28 fev. 2017.

CONSElHO FEDERAL DE CONTABILIDADE (CFC). Brasil. Perfil do Contabilista Brasileiro. 2009. Disponível em: <http://portalcfc.org.br/wordpress/wpcontent/uploads/2009/01/perfil_web.pdf>. Acesso em: 15 out. 2015.

CONSElho Federal De CONTABIlidade (CFC). Brasil. Perfil do Profissional de Contabilidade. 2013. Disponível em: <http://portalcfc.org.br/wordpress/wpcontent/uploads/2013/.../livro_perfil_2013_web2.pdf>. Acesso em: 15 out. 2015.

DECROP, Alain. Qualitative Research Pratice. A guide for social science students and researchers. Rechercher et Applications en Marketing, v. 19, p. 126-127, 2004.

DOWBOR, Ladislau; IANNI, Octavio; RESENDE, Paulo-Edgar. Desafios da Globalização. 3 ed. Rio de Janeiro: Vozes, 1997.

GIL, Antônio Carlos. Como elaborar projetos de pesquisa. 5. ed. São Paulo: Atlas, 2010.

HOLSTI, O. (1968) Content Analysis. In: CHIZOTTI, Antonio. Pesquisa qualitativa em Ciências Humanas e Sociais. Rio de Janeiro: Vozes, 2006.

KLIBI, Mohamed Favor; OUSSII, Ahmed. Skills and Attributes Needed for Success in Accounting Career: Do Employers' Expectations Fit with Students' Perceptions? Evidence from Tunisia. 2012.

INSTITUTO DE AUDITORES INDEPENDENTES DO BRASIL (IBACRON/São Paulo). A importância da Educação Continuada. 2014. Disponível em: $<$ http:/ /www.ibracon.com.br/ibracon/Portugues/detSalaImprensaRelease.php?cod=1947>. Acesso em: 23 jul. 2016.

LAKATOS, Eva Maria; MARCONI, Marina de Andrade. Fundamentos de Metodologia Científica. 5. ed. São Paulo: Atlas, 2003.

MARTINS, André Felipe Costa. As perspectivas profissionais dos alunos do curso de Ciências Contábeis da Universidade Federal de Goiás. 2017. Disponível em < https://repositorio.bc.ufg.br/bitstream/ri/14622/2/TCCG\%20-\%20Ciências\%20Contábeis\%20\%20André\%20Felipe\%20Costa\%20Martins\%20-\%202017.pdf> Acesso em 09 ago. 2018.

MIRANDA, Gilberto José et al. A pesquisa em Educação Contábil: produção científica e preferências de doutores no período de 2005 a 2009. Revista Contabilidade \& Finanças, v. 24, n. 61, p. 75-88, 2013.

MORGAN, David. Focus Group as qualitative research: Qualitivative Research Methods Series, 1997.

NASCIMENTO, Leonaldo Ferreira do; NIVEIROS, Sofia Ines; ARENHARDT, Ramon Luis. Educação Continuada como instrumento de atualização permanente do profissional contábil em Rondonópolis - 
MT In: CONGRESSO DE CONTROLADORIA E FINANÇAS. 2009, Santa Catarina. Anais... . Santa Catarina: UFSC, 2010. p. 1 - $17 . \quad$ Disponível em: < http://dvl.ccn.ufsc.br/congresso/anais/3CCF/20090816211052.pdf>. Acesso em: 05 mar. 2017.

NETTO, Carla; GIRAFFA, Lucia MM; FARIA, Elaine T. Graduações a distância e o desafio da qualidade. EDIPUCRS, 2010.

O GLOBO. Pós Graduações mais procuradas refletem crescimento econômico. 2017. Disponível em: < http://oglobo.globo.com/economia/emprego/pos-graduacoes-mais-procuradas-refletemcrescimento-economico-6823305>

OLIVEIRA, Florence de Senna; NASCIMENTO, Eduardo Mendes. Percepção dos profissionais da contabilidade mineiros sobre o Programa de Educação Profissional Continuada. Revista Brasileira de Contabilidade, n. 231, p. 80-95, 2018.

PASSOS, Ivan Carlin; DE ANDRADE MARTINS, Gilberto. Métodos de sucesso no ensino da contabilidade. Revista Brasileira de Contabilidade, n. 157, p. 61-79, 2006. Disponível em: < http://rbc.cfc.org.br/index.php/rbc/article/view/658 >. Acesso em: 09 ago. 2018.

RABELLO, Elaine T.; PASSOS, José Silveira. Vygotsky e o desenvolvimento humano. Formato do arquivo: Microsoft Powerpoint-Visualização rápida. www.ceesp. com. br/arquivos/Aula, v. 205, n. 20, p. 20, 2010.

\section{RAMIREZ, Neusa Oviedo. POLÍTICA DE EDUCAÇÃO SUPERIOR NO BRASIL: A EXPANSÃO DOS CURSOS DE CIÊNCIAS CONTÁBEIS (1996 a 2009). 2011.}

RICCIO, Edson Luiz; SAKATO, Marici Cristine Gramacho. Evidências da globalização na educação contábil: Estudo das grades curriculares dos cursos de graduação em universidades brasileiras e portuguesas. Revista de Contabilidade \& Finanças USP, São Paulo, n. 30, p.35-44, maio 2004. Disponível em: <http://www.scielo.br/pdf/rcf/v15n35/v15n35a03.pdf>. Acesso em: 20 jul. 2016.

SOUZA, Marcos Antonio de. DIEJL, Carlos Alberto. Formação, Certificação e Educação Continuada: Um estudo exploratório do Profissional Contábil sob a Ótica das Empresas Head Hunters. In: LOPES, Jorge. FILHO, José Francisco Ribeiro. PEDERNEIRAS, Marcleide. Educação Contábil: Tópicos de Ensino e Pesquisa. São Paulo: Atlas, 2008. Cap. 4, p. 51-74.

VIANNA, Carlos Eduardo Souza. Evolução histórica do conceito de educação e os objetivos constitucionais da educação brasileira. Revista Janus, ano 3, n. 4, págs. 129-138, 2006. Disponível em: < http://unifatea.com.br/seer3/index.php/Janus>. Acesso em 21 de setembro de 2019.

VERHINE, Robert E.; FREITAS, Antônio Alberto da Silva Monteiro de. A avaliação da educação superior: modalidades e tendências no ensino internacional. Revista de Ensino Superior Unicamp, Campinas, v. 7, n. 1, p.16-39, 2012. Trimestral. Disponível em: $<$ https://www.revistaensinosuperior.gr.unicamp.br/edicoes/ed07_outubro2012/ARTIGO_PRINCIPAL .pdf>. Acesso em: 20 jul. 2015.

WILL, Anderson Renan et al. Pós-Graduação em Ciências Contábeis no Brasil: Contexto e Processo de Seleção. In: XI COLÓQUIO INTERNACIONAL SOBRE GESTÃO UNIVERSITÁRIA NA AMÉRICA DO SUL, 11. 2011, Florianópolis. Proceedings.....Florianópolis: Iglu, 2011. p. 1 - 15. Disponível em: <https://repositorio.ufsc.br/bitstream/handle/123456789/29744/7.4.pdf?sequence=1>. Acesso em: 07 nov. 2016.

Recebido em: setembro de 2018. Aprovado em: setembro de 2019. 